\title{
Research on the Quality and Safety Management of Food Supply Chain
}

\author{
Qi Zhang \\ Beijing Wuzi University, Beijing, China \\ Email:Im2003@163.com
}

Received 3 June 2016; accepted 18 July 2016; published 25 July 2016

\begin{abstract}
As the severe food safety situation in China becomes an urgent problem to be solved, the emergence and development of "Farmer-Supermarket Direct-Purchase" model, to some extent, provides favorable conditions for the solution of food safety problem. The research of food safety control which is based on "Farmer-Supermarket Direct-Purchase "model involves the coordination and unification among government's macro-control, management structure of producer and supermarket. Based on the analysis of the factors and risks of "Farmer-Supermarket Direct-Purchase" management model, this article sets company $A$ as an example analyzing the specific processes and potential risks of supplier relationship management, procurement and distribution etc. in the process of quality and safety management of food supply chain, in order to provide suggestions for the improvement of the of China's food supply chain management efficiency.
\end{abstract}

\section{Keywords}

Farmer-Supermarket Direct-Purchase, Food Safety, Supplier Relationship

\section{Introduction}

There are many kinds of raw materials for food processing and endless production methods in our country, which increases the difficulty of the management of food safety problems. The imperfection of the corresponding rules and regulations and governance attitudes of the relevant departments also leaves large potential security hazard. Food safety problems could be said, "Always in governance, never be eliminated".

Controlling and managing the food supply chain as well as improving its entire "raw materials-processingmarketing" process have become the focus of public concern and government decision-making. How to improve the food safety level through effective supply chain management has become an important research subject [1].

\section{Analysis on the Causes of Frequent Incidents of Food Safety Problem}

\subsection{The Imperfection of Logistics System}

Due to the vast geographical environment of China, compared with the processing product with period of validity, agricultural products are more affected by this factor. In order to ensure the preservation of agricultural products, the agricultural products which is far from the place of origin usually enter the transportation process 
before maturity, resulting in the decline of agricultural products' quality. In addition, although the transportation network of agricultural products is relatively developed, transportation system is still inadequate and technology is fall behind. Agricultural products are affected by some factors such as freezing and leak etc, which will lead to the loss increase in transit. Inefficiency of long-time transport logistics and increasingly apparent contradiction between production and transportation are the important reasons for the problem of food safety in China.

\subsection{Information Asymmetry}

The circulation chain of food, including producers; suppliers; vendors; consumers and logistics parts, all of which are regulated by the corresponding regulatory authorities of the government. The ideal state is that government express information which is under its supervision to consumers, so that consumers could trust products. However, the real situation of the present society is that government's supervision of each links could not form a complete system and each regulatory parts' disconnection makes producers cannot understand consumers' real demand and makes consumers cannot understand the production process either [2]. As for producers, the information asymmetry makes producers generate fluky psychology, such as profiteering from illegal operation; as for consumers, the information asymmetry deepens consumers' mistrust of the entire logistics process [3], which greatly reduces the consuming desire. In general, the information asymmetry causes the producers and consumers to be trapped in a vicious circle.

\subsection{The Imperfection of Regulatory Measures}

For government, the negligence in the supervision of food safety in our country is much in evidence. China did not promulgate the" Food Safety Law "until 2009, and compared with other laws and regulations, the lag of "Food Safety Law" reflects the importance it attaches to the government's food safety supervision should be upgraded.

From food-production system, firstly, the food production standards are not comprehensive; Secondly, the rapid economic development speed makes the food producing and processing industry developed very fast. Compared with that, the relevant laws and regulations are stereotyped and updated slowly. Although from 2009 to the present, "Safety Law Food" has been revised for four times, the standard of food safety remained low.

\section{3. "Farmer-Supermarket Direct-Purchase" Model and Management Factors}

\section{1. "Farmer-Supermarket Direct-Purchase" Model}

"Farmer-Supermarket Direct-Purchase" model is a new model of circulation that the farmers provide agricultural products straightly to the supermarket, food market and grocery store according to the intentional agreement signed by farmers and merchants [4]. "Farmer-Supermarket Direct-Purchase "model is an innovation to optimize the supply chain of agricultural products in our country. In this model, supermarkets participate in the agricultural production, processing and circulation, using the advantages of market information, management method to provide technology, logistics, information etc. services to farmers, which could effectively connects small farmers with big markets and play the role of driving the market. In the traditional agricultural products marketing method, the process between production and sales is complicated which can be expressed as the following figure (see Figure 1).

In this pattern of circulation, the agricultural products go through many channels, as a result, the safety management of agricultural products is vulnerable to the vulnerability. The more links included, the more resistance of the food regulation. Due to the tediously flow, problems might occur in any links of the whole process from agricultural products leaving the factory to the transportation. Besides, lagging regulation makes the relationship between producers and consumers disconnected from each other. Once the food problems occur, checking the root of them will also become a new challenge. Therefore, the traditional method of selling agricultural products has many disadvantages, which is extremely unfavorable to the food safety supervision [5].

\subsection{Management Elements of "Farmer-Supermarket Direct-Purchase" Model}

1. Producer

In the food supply chain system that is under the "Farmer-Supermarket Direct-Purchase" model, the produc- 


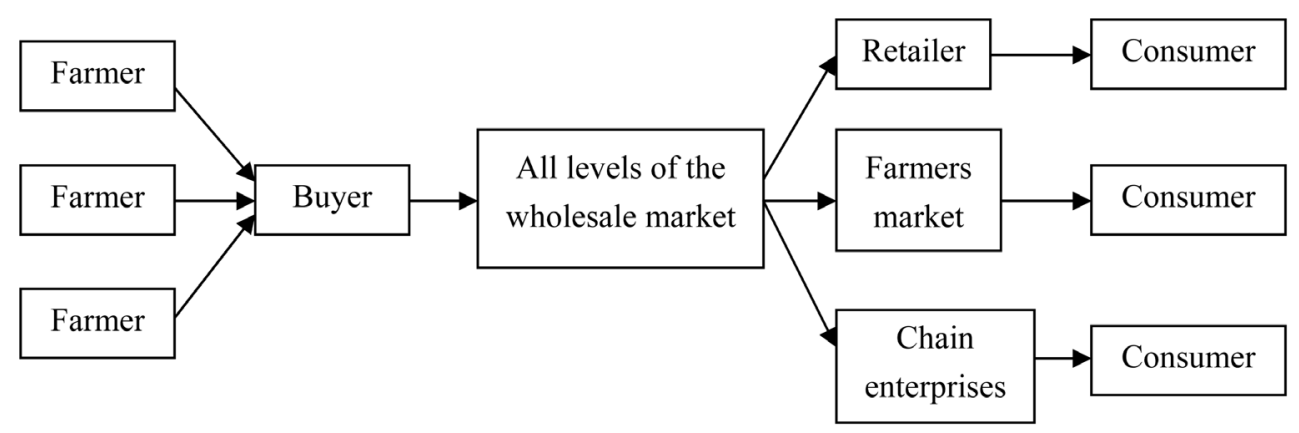

Figure 1. Raditional agricultural products marketing method.

ers or suppliers as the source of the whole supply chain system, should grasp the production part, which is the key to manage the entire supply chain. Therefore, the strategy which is made for producers is particularly significant.

To control the production source we must first strengthen the supervision of the use of agricultural inputs. Education levels of agricultural producers are lagging behind, a large number of rural merchants lack the knowledge of agricultural inputs and the effect of excessive agricultural inputs is obvious on the surface, which make rural merchants use agricultural input. Some material demonstrated that more than $70 \%$ agricultural products release pesticide at production time. The organic phosphorus pesticides accounted for $70 \%$ and highly toxic pesticide accounted for $70 \%$ in the organic phosphorus pesticides. Thus, the phenomenon of excessively releasing toxic pesticides at production time is extremely serious which makes it meaningful to work out the correct countermeasures for agricultural inputs [6]. In addition, the agricultural production should also adapt to the development of science and technology.

2. Intermediary

In the supply chain of "Farmer-Supermarket Direct-Purchase "model, as an intermediary, supermarket plays an important part of coordinating producers and consumers. Supermarket plays the role of undertaking the initial and the terminal in the whole supply chain. Supermarkets can use validity of contracts to restrict and guide, through legal channels, rural merchants to produce through proper channels. Besides, the suppliers' competition to the same supermarket could become the powerful constrained force, for rural merchants, of producing the agricultural and sideline products through proper channels. Controlling food safety in supermarkets is going to be the second barrier of controlling the food safety problem and it is the vertical integration of supply chain, as well as reduces the cost of understanding food safety information for consumers. At the same time, supermarkets could set up the relevant logistics systems [7], or to be the major or auxiliary transport for connecting supermarkets with rural merchants. Supermarkets can provide a greater convenience for rural merchants through their own logistic modes including freezing and refrigerate foods. At the same time the quality of products can be ensured and the cost could be cut down.

\section{Consumer}

Consumers as the terminal of the entire supply chain system is a very important. If there is no consumer wishes to buy after transportation, it will affect the economic cycle of this product. For a long time, the cumulative food safety issues make consumers fall into the confused misconceptions. In the "Farmer-Supermarket Direct-Purchase "model, we should strive to encourage consumers to build up the correct consumption concepts, accept the idea of regarding the quality and safety of agricultural products as the primary conditions in "Farmer-Supermarket Direct-Purchase "model and guide consumers to choose the agricultural and sideline products in natural state in the "Farmer-Supermarket Direct-Purchase "model instead of irrational consumption. The terminal guidance is conducive to the whole supply chain move toward to a more secure and reliable direction. In the "Farmer-Supermarket Direct-Purchase" model, both of the producers and the supermarkets have greatly reduced the cost. Under the existing policy of our country, the selling price would be reduced accordingly. Faced with the same quality products, consumers prefer the cheaper one, which makes consumers generate a positive effect on the product in this mode making it become more conducive to the implementation and development of the "Farmer-Supermarket Direct-Purchase "model in China's food circulation. Besides, some products that have quality problems almost have no difference with the safe products in the appearance, which requires consumers 
to strengthen the discrimination ability, understand the knowledge of food safety, and improve the awareness of food safety. Enhancing the food safety from consumers' side could prevent the unsafe food from entering the market in the terminal so as to avoid unsafe food hazards, strengthen the application of "Farmer-Supermarket Direct-Purchase” model in the market and encourage rural merchants and supermarkets to produce healthy food through proper channels for consumers [8].

4. Government Regulatory Authorities

For the implementation of "Farmer-Supermarket Direct-Purchase" model, the government should put forward more detailed policies and corresponding access standards. Similar to the inspection and access standards of meat, establish a comprehensive standard system for the detection of agricultural products and put label to the standards-compliant products, professionally expressing the safety of product to the consumers who have little knowledge of the information. At the same time, strengthening the supervision of this aspect, government intervention, strictly controlling the food quality, preventing the unsafe products from entering the market, ensuring the quality and safety of the agricultural products and guarding a pass for the healthy food chain [9].

\section{Case Analysis of "Farmer-Supermarket Direct-Purchase" Model}

\subsection{The Overview of Company A}

Company A is one of the world's largest chain companies calculated by turnover. Company A has more than 10,000 stores in 27 countries, 69 brands, more than 2,200,000 employees, which makes it become the chain corporation that has the highest share of employees in the world. Company A upholds "Respect for the individual, Customer service, Pursuit of excellence," the three principles, and adheres to the "Control the lower costs than competitors” strategy. According to "Fortune”, it keeps ranking first in Top500 corporations for three consecutive years, and it was awarded as the most value-effect brand. Company A entered the Chinese market in 1996 and established nearly 400 large shopping malls in China till now.

\subsection{The Application of "Farmer-Supermarket Direct-Purchase" Model in Company A}

1. Relationship management between company A and supplier in "Farmer-Supermarket Direct-Purchase” model

In supply chain management, if upstream clients built up integrated supply chain relationship with downstream companies, then the company will obtain strong competitiveness to provide better demand and service for consumers in the fierce market competition. Company A has consistently adhered to the low cost strategy, aiming at reducing all of the costs that may be generated during the operation process and benefiting consumers by the cost savings. Company A carries out the low-cost strategy and strictly selects suppliers at the same time, especially the food suppliers. The supplier selection method of company A firstly monitors the safety of food by product testing and sample inspection and other methods. If the food passes the detection and meets the relevant national food safety standards, it should go through the quality audit experts' on-site assessment of company A. If it passes the assessment, company A will sign the supply agreement with that food supplier. In this process, company A builds up the "Farmer-Supermarket Direct-Purchase” model making the agricultural products directly connect with supermarket. In order to enable consumers to buy the safe, reassuring and quality products, company A selects the procurement base according to the consumption demand, variety and other factors and adds the detection base environment and food safety of the base etc. multiple links to the traditional "Farmer-Supermarket Direct-Purchase” model. Company A’s unique "Farmer-Supermarket Direct-Purchase” model not only establishes cooperative relations with the healthy and safe agricultural producers, but also achieves the "habitats-sales" integration of the agricultural products, saving the transportation cost and making customers buy cheaply and buy at ease.

2. Procurement and logistics distribution management of company A in the "Farmer-Supermarket DirectPurchase" model

(1) Purchasing Management of Company A

Centralized Purchasing Model has always been the aspect that is highly recognized by the society and the commercial circles. Company A's purchasing process: first of all, the staff select a partner from multiple suppliers according to the purchasing plan. Then, identify a series of order details including time, packing, price, etc. 
Finally, introduce the product into market by the purchasing personnel. The whole process is expressed by the flow chart (Figure 2) as follows.

The products that company A purchases by "Farmer-Supermarket Direct-Purchase" model mostly comes locally from the Shenyang, thus eliminate many transportation and distribution links and greatly shorten the transportation and food storage time, which not only save the transportation cost but also is favorable for the food restock, increasing the freshness of food, making food sales' advantages outweigh the disadvantages. Furthermore, most of the suppliers are from the local, which facilitates the supplier management of company A, easy to carry out conduct site inspections at any time, so that the entire supply chain could be maintained more securely. The "nearest procurement" model of company A formed a divergent structure making the supermarkets as the center and numerous agricultural products suppliers as the terminal. Assembling the base products in front of customers, providing the freshest food for customers and reflecting company A's "customer service" business philosophy once again.

(2) Logistics Delivery Management of Company A

The logistics distribution system of company A ensures the low cost. First of all the suppliers deliver the goods according to the shipping order, and the distribution center delivery uniformly after summarizing the orders, then sent the products to each retail stores. The whole process is expressed by the flow chart (Figure 3 ) as follows.

Thus it can be seen that, company A's links of food distribution process are less than other companies. The fewer links in the supply chain, the more benefits to the supply and regulation of products. In the "Farmer-Supermarket Direct-Purchase" model, from suppliers to company A's retail stores, each link is under the control of company A, making the whole process transparent and easy to manage. Besides, company A combines the "Farmer-Supermarket Direct-Purchase" model with modern Internet technology, using the advanced satellite networks to locate the position of products, and greatly shortens the time from filling the orders to accept and deliver the orders.

At present, the problem of food safety increasingly attracts the attention of academic and business field. From the case of company A, "Farmer-Supermarket Direct-Purchase" model has established a harmonious supply chain with producer automation, intermediate self-discipline, rational consumption and government powerful regulation. The development of "Farmer-Supermarket Direct-Purchase" model in our country requires the effective integration and management of the Commercial Ecological Circle in the food industry to enhance the quality and safety of food supply chain management level. Although the "Farmer-Supermarket Direct-Purchase" model remains in the exploration and improvement phase, the future research could study the efficient logistics system construction of "Farmer-Supermarket Direct-Purchase" model according to the specific characteristics of the product and explore the operational index system of supplier selection.

(This paper is supported by 2016 High Level Research Funding Project, Beijing Wuzi University: the study on the basis of global value chain of the industry in Beijing, Tianjin and Hebei (Project number; 0541604646)

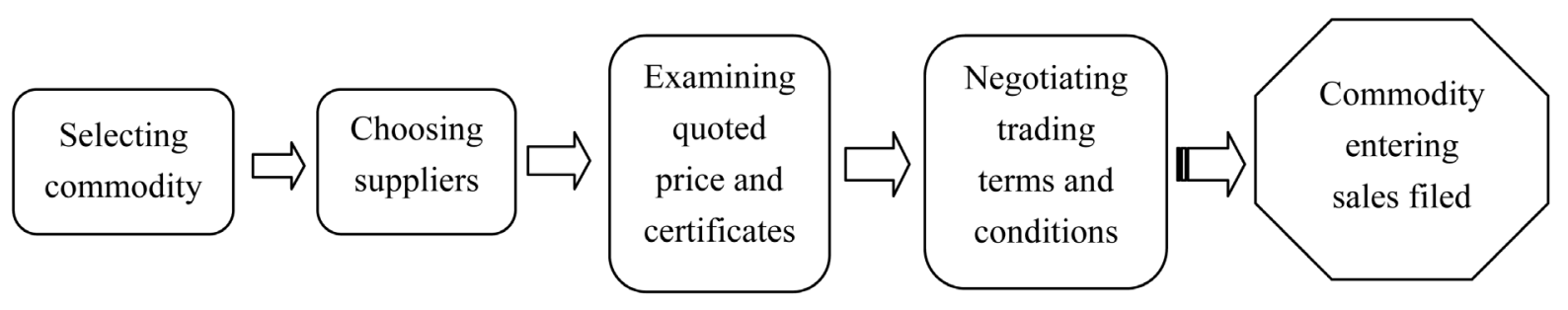

Figure 2. Procurement process of company A.

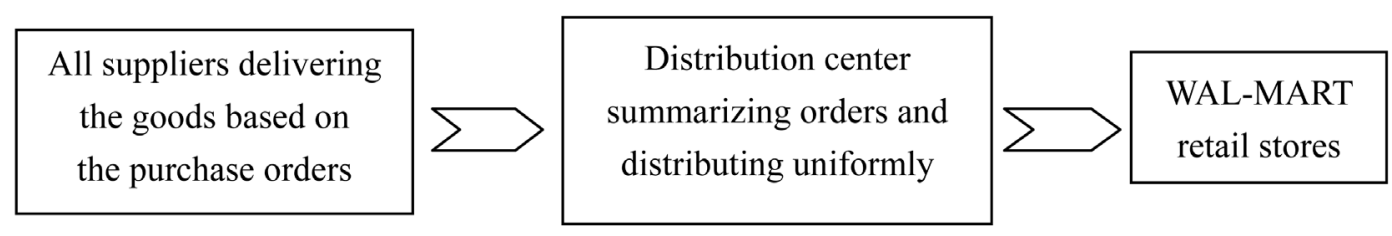

Figure 3. Logistics distribution process of company A. 
and it has received special subsidy from the joint-built project of Beijing Municipal Education Commission—Research on Public Service Incubator of Beijing Creative Industries and Small Companies.)

\section{References}

[1] He, W.Z. (2015) Study on Innovation of Agricultural Produce Supply Chain Management Based on Quality and Safety. Logistics Technology, No. 13.

[2] Vos, E. (2000) EU Food Safety Regulation in the Aftermath of the BSE Crisis. Journal of Consumer Policy, No. 3.

[3] Chapman, R.L., Soosay, C. and Kandampully, J. (2003) Innovation in Logistic Services and the New Business Model: A Conceptual Framework. International Journal of Physical Distribution \& Logistics Management, 33, 630-650. http://dx.doi.org/10.1108/09600030310499295

[4] Sacks, R., Yi, S.S. and Nonas, C. (2015) Increasing Access to Fruits and Vegetables: Perspectives from the New York City Experience. American Journal of Public Health, 105, E29-E37. http://dx.doi.org/10.2105/ajph.2015.302587

[5] Shi, S., Wei, L.B. and Wu, J.Q. (2012) Cooperation Performance and Its Surplus Allocation along Agri-Food Supply Chain during "Farmer-Supermarket Direct Purchase"-Evidence from the Mode of "Farmer + Cooperative + Supermarket”. China Rural Survey, No. 4.

[6] Wang, H.C., Xiao, J.H, Xie, K. and Wu, J.P. (2013) Food Safety Governance-A Study Combing Information Technology and Institutional Arrangement. China Industrial Economics, No. 3.

[7] Gong, Q. and Chen, F. (2012) The Impact of the Supply Chain Traceability on Food Safety and Corporate Profits. Nankai Economic Studies, No. 6.

[8] Yang, Y.Z. (2015) Research on "Farmer-Supermarket Direct-Purchase” Model from Supply Chain Perspective. China Business \& Trade, No. 26.

[9] Li, Z. (2013) Study on the Agricultural Product Safety Problem of “Farmer-Supermarket Direct-Purchase” Model. Gansu Social Science, No. 2.

\section{Submit or recommend next manuscript to SCIRP and we will provide best service for you:}

Accepting pre-submission inquiries through Email, Facebook, Linkedin, Twitter, etc

A wide selection of journals (inclusive of 9 subjects, more than 200 journals)

Providing a 24-hour high-quality service

User-friendly online submission system

Fair and swift peer-review system

Efficient typesetting and proofreading procedure

Display of the result of downloads and visits, as well as the number of cited articles

Maximum dissemination of your research work

Submit your manuscript at: http://papersubmission.scirp.org/ 